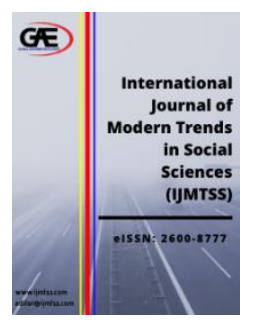

\author{
International Journal of Modern Trends in \\ Social Sciences (IJMTSS) \\ Journal Website: http://ijmtss.com/ \\ eISSN: $2600-8777$
}

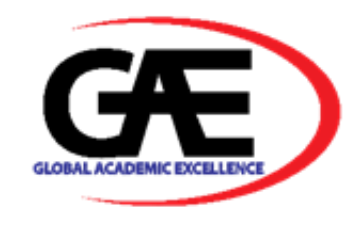

\title{
EFFECT OF PEOPLE BASED LEADERSHIP ON MOTIVATION TO PERFORM JOB
}

\author{
Azman Ismail ${ }^{1}$, Ishak Abd Rahman ${ }^{2}$, Asyakireen Samsudin ${ }^{3}$, Alvianny Voo Nyuk Chong @ \\ Albertus ${ }^{4}$
}

$1 \quad$ Faculty of Economy and Management. Universiti Kebangsaan Malaysia

Email: azisma08@gmail.com / azisma12@ukm.edu.my

2 Faculty of Economy and Management. Universiti Kebangsaan Malaysia

Email: haq@ukm.edu.my

3 Faculty of Economy and Management. Universiti Kebangsaan Malaysia

Email: syakanda1304@ukm.edu.my

$4 \quad$ Faculty of Economy and Management. Universiti Kebangsaan Malaysia

Email: alvianyvnc@yahoo.com

\section{Article Info:}

\section{Article history:}

Received date: 14.04 .2020

Revised date: 16.04 .2020

Accepted date: 02.06 .2020

Published date: 10.06 .2020

\section{To cite this document:}

Ismail, A., Abd Rahman, I., Samsudin, A., \& Alvianny, V. N. C. A. (2020). Effect of People Based Leadership on Motivation to Perform Job. International Journal of Modern Trends in Social Sciences, 3 (12), 2734.

DOI: $10.35631 /$ IJMTSS. 312003

\section{Abstract:}

This study measures the relationship between people-based leadership and motivation to perform using self-report questionnaires collected from the staff at a government research university in Peninsular Malaysia. The results of stepwise regression analysis confirm that participative and consultative styles were significantly correlated with motivation to perform a job. This result demonstrates that the ability of leaders to appropriately implement participative and consultative styles in performing daily job operations have increased employees' motivation to perform a job in the studied organization. Additionally, this study offers discussion, implications, and conclusions.

\section{Keywords:}

Participative Style, Consultative Style, Motivation to Perform Job 


\section{Introduction}

People based leadership (PBLP) is a person centred where leaders will form mutual respect, trust and confidence with followers, as well as motivate and inspire followers to accomplish their organizational strategic business vision and missions (Robbins \& Judge, 2013). According to many scholars such as Amabile et al. (2004), Yukl (2005), and Jong and Hartog (2007) said that PBLP consists of two major features: participative and consultative styles. Participative style (PARTS) is broadly defined as the willingness of leaders to closely work with their followers and involve them in making decisions to achieve daily work objectives. For example, many leaders usually practice participative style through general consultation, empowerment, joint decision-making and power sharing in performing daily job (Jong \& Hartog, 2007; Yukl, 2005). On the contrary, consultative style (CONSS) is often defined as the readiness of leaders to request brilliant opinions and ideas from their followers in achieving work objectives. For example, most leaders often practice consultative style through appreciation of followers' opinions and ideas in setting goals and assigning daily tasks (Berson \& Avolio, 2004; Jong \& Hartog, 2007).

A review of the present literature pertaining to workplace leadership mostly published in the $21^{\text {st }}$ century reveals that the capability of leaders to properly implement PARTS and CONSS in planning and administering daily job functions may have a significant impact on personal outcomes, especially motivation to perform job. Findings by Monika Rolkováa (2015) demonstrated that empowerment of employees is not on high level and the companies should consider including employee empowerment techniques as components of management development programs. Study by Clement Bell (2014) showed that participative and directive leadership have positive and significant impact on organisational culture. However, directive leadership has negative and insignificant impact on adaptability. The results also indicated that participative and directive leadership combined have no additive impact on organisational culture.

In an organizational behaviour perspective, motivation to perform job (MTJOB) is often defined as the reason people want to work and to be successful. Motivation in work setting may be driven not only by internal rewards and also external rewards (Milkovich et al., 2014; Murphy, 2015.

Within an organizational leadership model, many scholars concur that PARTS, CONSS and MTJOB have different meanings, but highly interrelated constructs. For example, leaders who have the capabilities to properly implement participative and consultative styles in handling daily job functions may lead to an enhanced job satisfaction (Yiing \& Ahmad, 2009; Ismail, Zainuddin \& Ibrahim, 2010; Ismail et al., 2010; Gharibvand et al., 2013), and organizational commitment (Hulpia et al., 2009; Tabbodi, 2009; Yousef, 2000; Ismail et al., 2010). Although this relationship has extensively been studied, the predicting role of PBLP is given less emphasized in the leadership behavior research literature (Brown, 2003; Tabbodi, 2009; Hulpia et al., 2009; Yousef, 2000; Nguni et al., 2006). Therefore, this situation inspires the researchers to fill in the gap of literature by examining the effect of PBLP on MTJOB. Specifically, this study intends to answer two major objectives: first, to investigate the relationship between PART and MTJOB. Second, to examine the relationship between CONSS and MTJOB.

\section{Problem Statement}

There are various dimensions of research to associate factors that influence job performance with decision making style have been conducted for example by Ismail Hussein Amaza \& 
Abdul Rahman Idrisa (2011), Sai Mei Ling (2014) has conducted a research to study the relationship between job control, social support and job performance, Mahiswaran (2016) has conducted a study on working environment, motivation and job performance. Other researchers such as Sara Ghafari (2017) has done a study on relationship between job performance and responsibility and whilst Lai Chee Yee (2018) made a research on job satisfaction and job performance. However, leadership factors have not been focused on by those past studies. Therefore, it is important that this study will focus on the relationship between leadership style and its contribution to motivating employees in performing their job.

The relationship between PBLP and personal outcomes is consistent with the notion of leadership theory. For example, path-goal theory (House, 1971, 1996; House \& Mitchell, 1974) explains that the ability of leaders to clarify the right path will guide followers to achieve their goals (House, 1971, 1996; House \& Mitchell, 1974). On the contrary, leader member exchange theory (Dienesch \& Liden, 1986; Gomez \& Rosen, 2001) suggests that relationship quality between leaders and followers may induce positive follower behaviour. Application of these theories in an organizational leadership shows that the notion of path-goal and quality of the relationship is often translated as participative and consultative styles. The notion of these theories has gained strong support from PBLP research literature. Several recent studies were conducted using a direct effects model to examine PBLP in diverse organizational settings, such as 1440 employees in variety of organizations (Ocholi, 2005), 283 individuals from broad cross-section of job types in several industries in US (Picollo \& Colquitt, 2006), and 100 employees in one city based local authority in Sarawak, Malaysia (Ismail, Yahya, Hamid \& Ting, 2009). These surveys showed that the ability of leaders to appropriately practice participative and consultative styles in executing daily work has been a major determinant of motivation to perform job in the organizations studied (Ocholi, 2005; Picollo \& Colquitt, 2006; Ismail, Yahya, Hamid \& Ting, 2009). Thus, it can be hypothesized that:

H1: There is a positive relationship between participative style and motivation to perform job. $\mathrm{H} 2$ : There is a positive relationship between consultative style and motivation to perform job.

\section{Methodology}

A cross-sectional research design was employed because it allowed the researcher to combine the leadership research literature and the actual survey as the main procedure to collect data for this research. Utilizing this procedure may assist the researcher to collect precise data, minimize bias and enhance the quality of data being collected (Cresswell, 1998; Sekaran, 2000). This study was conducted at a Malaysian public research university in Peninsular Malaysia. At the early stage of this study, the survey questionnaire was constructed based on the PBLP literature. After that, a back to back translation technique was employed to translate the content of survey questionnaire into Malay and English languages in order to enhance the validity and reliability of research findings (Hulland, 1999; Sekaran, 2000).

The survey questionnaire has three major sections. Firstly, PARTS had six items adapted from participative leadership behaviour literature (Jong \& Hartog, 2007; Likert, 1967; Yukl, 2005; Yousef, 2000). Secondly, CONSS had five items adapted from consultative leadership behaviour literature (Bennis, 1985; Jong \& Hartog, 2007; Likert, 1967; Yousef, 2000). Thirdly, MTJOB had fourteen items adapted from motivation to perform literature. All these items were assessed using a 7-item scale ranging from "strongly disagree/dissatisfied" (1) to "strongly agree/satisfied" (7). Demographic variables were used as controlling variables because this research emphasized on employee attitudes. 
A purposive sampling plan was used to distribute 200 survey questionnaires to employees in the organization. Of the total number, 130 (65 percent) usable survey questionnaires were returned to the researchers. Participants of this study answered the questionnaires based on their consents and a voluntary basis. Further, the Statistical Package for Social Science (SPSS/PC+ version 23.0) was used to analyse the survey questionnaire data and test the research hypotheses.

\section{Findings}

Most respondents were female (58 percent), age from 25 to 34 years old ( 55 percent), married employees (69 percent), held Malaysian Certificate of Education (37 percent), supporting staff (82 percent), working experiences from 6 to 10 years (29 percent), and monthly salary between Malaysia Ringgit, RM1000 to RM2499 (53 percent).

The factor analysis with varimax rotation and Kaiser-Mayer-Olkin test were done for 25 items, which represent four variables: PARTS, CONSS and MTJOB. The results of these tests showed that: first, all research variables exceeded the acceptable standard of Kaiser-Meyer-Olkin's value of 0.6 , and all research variables were significant in Bartlett's test of sphericity. These results indicated that all variables met the acceptable measures of sampling adequacy. Second, the items for each research variable exceeded factor loadings of 0.40 , and all research variables had eigenvalues larger than 1, indicating that the items which represent the variables and the variables met the acceptable measures of validity analysis (Hair, Anderson, Tatham \& Black, 1998). Further, all research variables exceeded the acceptable standard of reliability analysis of 0.70, indicating that the variables had high internal consistency (Nunally \& Bernstein, 1994). These results indicated that the measurement scale met the acceptable standard of validity and reliability analyses.

The variables had mean values are between 5.3 and 6.0, signifying that the level of PARTS, CONSS and MTJOB were ranging from high (4) to highest level (7). While, the correlation coefficients for the relationship between the independent variable (i.e., PARTS and CONSS) and the dependent variable (i.e., MTJOB) were less than 0.90, indicating the data were not affected by serious collinearity problem (Hair et al., 1998). Further, the reliability values for all variables were 1, indicating the variables met the standard of reliability analysis (Hair et al., 1998).

Table 1 shows that the inclusion of PARTS and CONSS in the analysis had explained 59 percent in the variance of MTJOB. This result indicates that it provides strong support for the model (Cohen, 1988). Further, the results of testing the hypotheses displayed that PARTS and CONSS were found to be significant predictors of MTJOB $(\beta=.42, p<0.001 ; \beta=.49, p<0.001$, respectively), therefore $\mathrm{H} 1$ and $\mathrm{H} 2$ were supported. This result confirms that PARTS and CONSS act as an important predictor of MTJOB in the organizational sample.

Table 1: Results of Testing $\mathrm{H1}$ and $\mathrm{H} 2$

\begin{tabular}{|l|c|}
\hline \multicolumn{1}{|c|}{ Variables } & $\begin{array}{c}\text { Dependent Variable } \\
\text { (MTJOB) }\end{array}$ \\
\hline Independent Variables & $0.42^{* * *}$ \\
PARTS & $0.49 * * *$ \\
CONSS & 0.59 \\
\hline R Square & \\
\hline
\end{tabular}




\begin{tabular}{|l|c|}
\hline Adjust R Square & 0.29 \\
R Square change & $0.28 * * *$ \\
F & $6.92 * * *$ \\
F Change R Square & $25.49 * * *$ \\
\hline
\end{tabular}

Note: Significant at $* *<0.01, * * * \mathrm{p}<0.001$

\section{Discussion and Implication}

This study shows that PBLP and CONSS act as an important predictor of personal outcomes. In the context of the study, leaders have used people-based leadership to manage followers in order to accomplish strategic business vision and missions as outlined by their stakeholders. Majority participants view that the levels of PARTS, CONSS and MTJOB are high. This situation explains that leaders have sufficient capabilities to carry out PBLP and CONSS in executing daily job and this may lead to higher MTJOB in the organization.

This study provides three major implications: theoretical contribution, robustness of research methodology, and contribution to practitioners. In terms of theoretical contribution, this study reveals that ability of leaders to appropriately implement PBLP and CONSS in performing day to day job operation may lead to greater JOBS and ORGC in the organization. This result is consistent with studies done by Yousef (2000), Yiing and Ahmad (2009), Tabbodi (2009), and Ismail, Zainuddin and Ibrahim (2010).

With respect to the robustness of research methodology, the survey questionnaire data have met the acceptable standards of validity and reliability analyses, this may lead to produced accurate and reliable findings. Regarding to practical contribution, the findings of this study can be used as guidelines by practitioners to improve the leadership behaviour in organizations. In order to perform this objective, top management should pay more attention of the following aspects: first, promotion criteria for management positions should be revised in order to recognize employees who have good academic qualifications, management skills, service records, proactive personalities and good moral values. Second, performance pay rises for excellent management employees should be upgraded in order to appreciate their efforts in developing and facilitating followers to achieve key performance indicators. Third, leadership development program curriculum should be updated according to current organizational transformation strategies and goals. For example, the content of development program should focus on equipping leaders with necessary knowledge, up to date skills, latest cognitive and emotional abilities, positive attitudes and other capabilities needed in present organizations. Hence, interactive development methods, such as team building, soft skills and case studies should be well organized to enable leaders mastering the learning content and apply it to solve problems in the real workplace. Four, the type, level and/or amount of reward should be increased in order to help employees fulfil basic necessities and decrease their financial burdens. If these suggestions are paid more attention this may motivate followers to support the organizational strategy and goals.

\section{Conclusion}

This study shows that PARTS and CONSS are important determinant of MTJOB in the organizational sample. This finding also has supported and broadened previous studies mostly published in Western countries. Therefore, the current research and practice in workplace leadership need to consider PARTS and CONSS as crucial elements of PBLP domain. The results of this study further suggest that the capability of leaders to appropriately implement 
people-based leadership in performing daily job may strongly enhance positive employee outcomes (e.g., satisfaction, commitment, ethics and trust). Thus, these positive outcomes may lead to maintaining and enhancing the organizational performance in an era of globalization.

The above conclusion should cautious with several limitations of this study. First, a crosssectional research design used in this study has not explained detail causal relationships amongst sub-samples within the sample of this study. Second, potential respondent characteristics are included in testing the relationship between the independent variable and the dependent variable. Third, this study has not assessed the relationship between dimensions for the independent variable and the dependent variable. Four, response bias cannot be avoided because the participants' answers are often affected by their personal judgements and emotions. Finally, survey questionnaire data taken from a purposive sampling plan are only able to represent general perceptions of certain participant characteristics in the organization. These limitations may decrease the ability to generalize the results of this study to other organizational backgrounds.

\section{References}

Allen, N., \& Meyer, J. (1990). The measurement and antecedents of affective, continuance, and normative commitment to the organization. Journal of Occupational Psychology, 63, 1-18.

Alonderiene, R., \& Majauskaite, M. (2016). Leadership style and job satisfaction in higher education institutions. International Journal of Educational Management, 30 (1), 140164.

Amabile, T. M., Srchatzel, E. A., Moneta, G. B., \& Kramer, S. J. (2004). Leader behaviours and the work environment for creativity: Perceived leader support. Leadership Quarterly, 15 (1), 5-32.

Bennis, W., \& Nanus, B. (1985). Leaders: The strategies for taking charge. New York: Harper \& Row.

Berson, Y., \& Avolio, J. (2004). Transformational leadership and the dissemination of organizational goals: A case study of a telecommunication firm. The Leadership Quarterly, 15(5), 625-646.

Bohlander, E., Snell, S., \& Sherman, A. (2001). Managing human resources. London: South Western College.

Brown, B.B. (2003). Employees' organizational commitment and their perception of supervisors' relations-oriented and task-oriented leadership behaviours. Unpublished doctoral dissertation. Virginia Polytechnic Institute and State University.

Clement Bell, Murugan Chan (2014) The Impact of Participative and Directive Leadership on Organisational Culture: An Organisational Development Perspective. Mediterranean Journal of Social Sciences MCSER Publishing, Rome-Italy Vol 5 No 23

Cohen, J. (1988), Statistical Power Analysis for the Behavioural Sciences. Hillsdale, N.J.: Lawrence Erlbaum.

Cresswell, J.W. (1998). Qualitative inquiry and research design: choosing among five traditions.London, UK: SAGE publications.

Dienesch, R.M., \& Liden, R.C. (1986). Leader-member exchange model of leadership: A critique and further development. Academy of Management Review, 618-34.

Feinstein, A.H. (2002). A study of relationships between job satisfaction and organizational commitment among restaurant employees. Journal of Managerial Psychology, 23(7), $33-57$. 
Fletcher, C., \& Williams, R. (2005). Performance management, job satisfaction and organizational commitment. British Journal of Management, 7(2), 169-179.

Gharibvand, S., Mazumder, M.N.H., Mohiuddin, M., \& Su, Z. (2013). Leadership Style and Employee Job Satisfaction: Evidence from Malaysian Semiconductor Industry. Transnational Corporations Review, 5(2), 93-103.

Gomez, C., \& Rosen, B. (2001). The leader-member exchange as a link between managerial trust and employee empowerment. Group \& Organization Management, 26(1), 53-69.

Hair, J.F., Anderson, R.E., Tatham, R.L., \& Black, W.C. (1998). Multivariate data analysis. New Jersey: Prentice Hall International, Inc.

House, R.J. (1971). A path-goal theory of leader effectiveness. Administrative Science Quarterly, 16, 321-339.

House, R.J. (1996). Path-goal theory of leadership: Lesson, legacy, and a reformulated theory. Leadership Quarterly, 323-52.

House, R.J., \& Mitchell, T.R. (1974). Path-goal theory of leadership. Contemporary Business, 3 (Fall), 81-98.

Hulland, J., 1999. Use of Partial Least Square (PLS) in strategic management research: A review of four recent studies. Strategic Management Journal 20 (2), 195-204.

Hulpia, H., Devos, G., \& Rosseel, Y., 2009. The relationship between the perceptions of distributed leadership in secondary schools and teachers' and teacher leaders' job satisfaction and organizational commitment. School Effectiveness and School Improvement, 20(3), 291-317.

Ismail, A., Shaik, A.R., Md Som, H., Saludin, M.N., Mohamed, H.A., Nordin, R., Zainudi, N.F.A. (2010). Relationship between leaders and followers as a predictor of organizational commitment and job satisfaction. 5th National Human Resource Management Conference 2010, 8-10 June 2010, Universiti Utara Malaysia.

Ismail, A., Zainuddin, N. F. A., \& Ibrahim, Z. (2010). Linking participative and consultative leadership styles to organizational commitment as an antecedent of job satisfaction. Unitar E-Journal, 6, 11-26.

Ismail Hussein Amazta *, Abdul Rahman Idrisa. (2011). Lecturers' Satisfaction towards University Management \& Decision-making Styles in some Malaysian Public Universities. Procedia Social and Behavioral Sciences 15 3957-3970

Jong, P.J de., \& Hartog, D.N.D. (2007). How leaders influence employees' innovative behaviour. European Journal of Innovation Management, 10, 41-64.

Invancevich, J.M., Konopaske, R.R., \& Matteson, M.T. (2008). Organizational behavior and management. New York: McGraw-Hill International.

Lai Chee Yee (2018). An Analysis on the Relationship between Job Satisfaction and Work Performance among Academic Staff in Malaysian Private Universities of Business. Journal of Arts \& Social Sciences Vol 1, Issue 2, 64-73

Likert, R., 1967. The human organization: Its management and values. New York, US: McGraw-Hill.

Locke, E.A. (1976). The nature and causes of job satisfaction. In Dunnette, M.D. (Eds). Handbook of Industrial and Organizational Psychology (pp. 1297-349). Chicago, IL: Rand McNally.

Mahiswaran Selvanathan , Sugumaran Selladurai , Ganibay Madina , Radziah Abdul Rahman \& Noor Shemah Mohamed Shaik Dawood.(2016)A Study on Employee's Motivation towards Employee Performance in Private University, Selangor, Malaysia.International Journal of Business and Management; Vol. 11, No. 7; ISSN 1833-3850 E-ISSN 1833-8119 
Maryam, A.S., Bader, A.E., \& Mohd. Nishat, F. (2017). Influence of organizational culture and leadership style on employee satisfaction, commitment and motivation in the educational sector in Qatar. EuroMed Journal of Business, 12 (2), 163-188.

McShane, S.L., \& Von Glinow, M.A. (2005). Organizational behavior. Tata, India: McGrawHill Inc.

Meyer, J. P., Allen, N. J., \& Gellatly, I. R. (1990). Affective and continuance commitment to the organization: Evaluation of measures and analysis of concurrent and time-lagged relations. Journal of Applied Psychology 75, 710-720.

Monika Rolkováa Viera Farkašováa (2015) The Features of Participative Management Style Procedia Economics and Finance 23, 1383 - 1387

Morrow, P. (1993). The theory and measurement of work commitment. Greenwich, CT.: JAL.

Nguni, S., Sleegers, P., \& Denessen, E. (2006). Transformational and transactional leadership effects on teachers' job satisfaction, organizational commitment, and organizational citizenship behaviour in primary schools: The Tanzanian case. School Effectiveness and School Improvement, 17(2), 145-177.

Nunally, J. C., \& Bernstein, I. H. (1994). Psychometric Theory. McGraw-Hill, New York.

Rad, A.M.M., \& Yarmohammadian, M.H. (2006). A study of relationship between managers' leadership style and employees' job satisfaction. Leadership in Health Services, 19 (2), 11-28.

Sai Mei Ling and Muhammad Awais Bhatti(2014).Work Stress and Job Performance in Malaysia Academic Sector: Role of Social Support as Moderator British Journal of Economics, Management \& Trade 4(12): 1986-1998, SCIENCEDOMAIN international www.sciencedomain.org

Sara Ghaffari,Dr. Ishak Mad Shah, Dr. John Burgoyne, Dr. Mohammad Nazri, Jalal Rezk Salleh: The Influence of Motivation on Job Performance.(2017): A Case Study at Universiti Teknologi Malaysia Australian Journal of Basic and Applied Sciences, 11(4) March, Pages: $92-99$

Sekaran, U. (2000). Research methods for business: A skill building approach. New York: John Wiley \& Sons, Inc.

Spector, P. E., 1997. Job satisfaction: Application, assessment, cause and consequences. Thousand Oaks, CA: Sage Publications, Inc.,

Tabbodi, M.T. (2009). Effects of leadership behaviour on the faculty commitment of humanities departments in the University of Mysore, India: Regarding factors of age group, educational qualifications and gender. Educational Studies, 35(1), 21-26.

Yiing, L. H., \& Ahmad, K. Z. B. (2009). The moderating effects of organizational culture on the relationships between leadership behaviour and organizational commitment and between organizational commitment and job satisfaction and performance. Leadership \& Organization Development Journal, 30(1), 53-87.

Yukl, G. (2002). Leadership in organizations. New Jersey, US: Prentice-Hall, Englewood Cliffs.

Yousef, D. A. (2000). Organizational commitment: A mediator of the relationships of leadership behavior with job satisfaction and performance in a non-Western country. Journal of Managerial Psychology 15 (1), 6-24. 